\title{
Neuropharmacology of the Injured Spinal Cord
}

\author{
R. G. Hill \\ Parke-Davis Research Unit, Addenbrooke's Hospital Site, Hills Road, Cambridge \\ $C B 22 Q B$, England
}

Paraplegia is a condition that has hitherto not received much help from pharmacology but new developments in this area of research may lead to worthwhile advances in the future. We now have an extensive insight into the way in which neurones within the spinal cord communicate with one another using neurotransmitters and some drugs are available that will mimic or block the effects of these substances. We are also just beginning to understand the consequences of lesions of the central nervous system on communication between neurones, and may within the next 10 years know how to make damaged neurones grow functional new processes that will bridge areas of damage.

Excitation of neurones within the dorsal horn of the spinal cord by impulses carried in the dorsal roots is now thought to be predominantly due to release of the excitatory amino acid neurotransmitters, glutamate and aspartate. Large diameter fibres may use the excitatory amino acids exclusively but smaller fibres appear to contain other substances in addition, notably peptides such as substance $\mathrm{P}$. This topic was dealt with in some detail in a recent review (Salt and Hill, 1983). The receptors for excitatory amino acids have been classified into three types on the basis of responses to three unnatural amino acids called kainate, quisqualate and N-methyl-D-aspartate (NMDA) (Watkins and Evans, 1981). The objective of most work on excitatory amino receptors is the production of antagonists that will block the actions of synaptically released transmitters. Agents that block the kainate and quisqualate receptor in a selective way have not yet been discovered, but potent and selective NMDA receptor antagonists are now available (Davies et al., 1986). The activity of transmitters acting at the NMDA receptor can also be modulated by drugs which do not act directly on the receptor (i.e. will not compete for NMDA binding) but at an adjacent site, possibly the ion channel through which the action of the excitatory amino acids is expressed. Initial observations on this mechanism were made with drugs such as ketamine which also have other effects, but now a potent and selective agent MK-801 is available (Wong et al., 1986). This compound has the advantage over the currently available receptor blockers of being absorbed after oral administration and it is currently being evaluated clinically as an anticonvulsant. 
The clinical relevance of agents blocking spinal NMDA receptor mediated actions of excitatory amino acids is twofold. Firstly, reduction of excessive sensory input to motoneurones that have been deprived of their normal descending inhibition could provide a useful antispastic effect and, secondly, as it has now been suggested that some disorders that show neuronal degeneration may be due to excessive activity in excitatory amino acid systems, blocking NMDA receptors may provide useful protection in patients at risk. In animal experiments $\mathrm{MK}-801$ has already been shown to be effective at protecting neurones in the striatum from the damaging effects of excitatory amino acids (Foster et al., 1987).

The two principal inhibitory transmitters in the spinal cord, GABA and glycine are also amino acids and as their actions have been studied since the 1960s they will not be considered in detail here. A recent and relevant observation however is that of one of the subtypes of GABA receptor, the GABA $_{B}$ site has been localised to the terminals of primary afferent terminals in the dorsal horn (Price et al., 1984). It now appears that the antispastic and weak analgesic properties of the $\mathrm{GABA}_{\mathrm{B}}$ agonist baclofen can be explained by a reduction in excitatory transmitter release consequent on an action at these presynaptic receptors.

Much current effort is being invested in studying the location and function of neuropeptides within the spinal cord, and it has recently been shown that substance $P$ levels in human CSF decrease with age (Tam et al., 1985). The excitatory peptides such as substance $P$ cannot be examined in the detail that is desirable as specific antagonists for their receptors within the spinal cord are not available. An advance in this area has resulted from the use of antibodies to antagonise the physiological actions of endogenous substance $P$ to establish that this peptide operates slow excitatory transmission in the dorsal horn of the rat (Randic et al., 1986). Specific antibodies may eventually have a therapeutic use as transmitter antagonists if the problem of penetration of the blood brain barrier can be solved.

The inhibitory peptides that have received most attention to date are the endogenous opioids. It is now recognised that these substances have important physiological and possibly pathological effects within the central nervous system. Naloxone, an antagonist of opioid peptide action, has been shown to have beneficial effects in experimental spinal injury particularly in respect of the associated blood flow changes (Faden, 1983). Recently WIN 44441 (which has increased antagonist properties at the kappa receptor compared with naloxone but similar mu antagonist actions) has been claimed to be superior to naloxone in such experiments, and to promote neurological recovery following spinal ischaemia (Faden and Jacobs, 1985). In addition to the well known ability of opioid agonists to produce analgesia, when given epidurally or intrathecally, it has now been shown that morphine given by these routes will produce effective control of intractable spasticity in quadriplegic patients (Erickson et al., 1985), and it will be interesting to evaluate the action of more recently developed opioids (such as those selective for the kappa receptor) in this condition.

The most exciting recent pharmacological advances are in the treatment of spinal cord trauma. It now seems that spinal cord injuries will eventually be treatable with drugs such that secondary deterioration will not occur and 
primary damage is repaired. Animal experiments have shown that only a proportion of descending neurones are needed to allow locomotion providing secondary ischaemic damage is prevented with appropriate drugs (opioid antagonists, 5-hydroxytryptamine antagonists and possibly catecholamine agonists) (Sabel and Stein, 1986). Two groups of substances have been shown to enhance restoration of function within the central nervous system. Monosialic gangliosides appear to be able to potentiate the action of endogenous trophic factors and thereby enhance regeneration, whereas nerve growth factor appears to act directly to enhance neuronal survival. Both treatments seem to act by rescuing surviving neurones rather than by causing regeneration of irreversibly damaged axons (Sabel and Stein, 1986).

The current state of spinal cord pharmacology is thus a healthy one, with a number of research studies in progress at present that may lead to real benefit in the future for those with paraplegia.

\section{References}

Davies J, Evans RH, Herrling PL, et al., 1986 CPP, a new potent and selective NMDA antagonist. Depression of central neuron responses, affinity for $\left[{ }^{3} \mathrm{H}\right] \mathrm{D}-\mathrm{AP} 5$ binding sites on brain membranes and anticonvulsant activity. Brain Research 382:169-173

ERICKSON DL, BlaCKLock JB, MiChaelson M, et al., 1985 Control of spasticity by implantable, continuous flow morphine pump. Neurosurgery 16:215-217

FADEN AI 1973 Opiate antagonists in the treatment of stroke. Current Concepts in Cerebral Disorders 18:27-31

FADEN AI, JACOBS TP 1985. Opiate antagonist WIN 44,441-3 stereospecifically improves neurologic recovery after ischaemic spinal injury. Neurology 35:1311-1315

FOSTER AC, GILL R, WoOdRUFF GN 1987 MK-801 prevents degradation of striatal neurones caused by instrastriatal injection of quinolinic acid. British fournal of Pharmacology 90

Price GW, Wilkin GP, Turnbull MJ, Bowery NG 1984 Are baclofen-sensitive GABA receptors present on primary afferent terminals of the spinal cord? Nature 307:71-74

RANDIC M, RYU PD, URBAN L 1986 Effects of polyclonal and monoclonal antibodies to substance $P$ on slow excitatory transmission in rat spinal dorsal horn. Brain Research 383:15-27

SABEL BA, STEIN DG 1986 Pharmacological treatment of central nervous system injury. Nature 323:493

SALt TE, Hill RG 1983 Neurotransmitter candidates of somatosensory primary afferent fibres. Neuroscience 10: 1083-1103

TAM PKH, Dockray GJ, Lister J 1985 Substance P concentrations in human cerebrospinal fluid vary inversely with age. Neuroscience Letters 54:327-332

Watkins JC, Evans RH 1981 Excitatory amino acid transmitters. Annual Review of Pharmacology and Toxicology 21:165-204

Wong EHF, Kemp JA, Priestley T, et al., 1986 The anticonvulsant MK-801 is a potent Nmethyl--D-aspartate antagonist. Proceedings of the National Academy of Sciences 83:7104-7108 